\title{
SKEPTICISM: IMPRACTICAL, THEREFORE IMPLAUSIBLE
}

\author{
Michael Hannon \\ University of Nottingham
}

\begin{abstract}
The truth of skepticism would be depressing and impractical. Our beliefs would be groundless, we would know nothing (or almost nothing) about the world around us, and epistemic success would likely be impossible. But do these negative consequences have any bearing on the truth of skepticism? According to many scholars, they do not. The impractical consequences of skepticism are typically regarded as orthogonal to its truth. For this reason, pragmatic resolutions to skepticism are regularly dismissed. I will argue, however, that skepticism is implausible because it is impractical. In particular, skepticism is implausible because it goes against the point of epistemic evaluation.
\end{abstract}

\section{Introduction}

Anti-skeptical views come in many forms. There is the heroic quest to refute the skeptics on their own turf. There is the attempt to show that skepticism is self-defeating. There is the argument that skeptics are merely redefining the word 'knows' and imposing artificially high standards. There is the pragmatic view that skepticism is unlivable: the skeptic will be unable to act, or she will be unable to live a normal life. ${ }^{1}$

This last objection, according to Allan Hazlett, is "probably the most instinctive and common and historically important objection to skepticism" (2014: 21). Put more broadly, the charge is that skepticism is, in some sense, impractical. Let's call proponents of this view "pragmatic anti-skeptics".

Pragmatic resolutions to skepticism are frequently dismissed. The consequences of skepticism might be bad or impractical for us, but this fact is believed to have little, if any, bearing on the truth of skepticism. We find this idea in Hazlett's book, A Critical Introduction to Skepticism: 
question of whether you know that you have hands. And so it is orthogonal to Cartesian skepticism. The defender of an argument is committed to the truth of its conclusion, not its practicality. (Hazlett 2014: 94)

Many epistemologists agree. As Diego Machuca (2015: 482) says, "it is plainly a non sequitur to argue that the excruciating practical and emotional effects of skepticism entail that it is false or that it ought not to be considered as a valid philosophical alternative." In his criticism of Crispin Wright's entitlement-strategic way with skepticism, Duncan Pritchard says:

This is, at best, merely a pragmatic resolution of the skeptical paradox, since it simply notes that accepting the skeptical conclusion would lead us to absurdity and intellectual stasis and then argues on this basis that we must reject it and therefore accept the legitimacy of our ultimately groundless believing. That...is not, however, an epistemic reason for thinking that such beliefs are true, but merely a pragmatic consideration which counts in favor of our proceeding as if they are true. Non-skepticism is thus defended on the grounds that it is the practical alternative, but we knew that already. Despite the well-advertised claims to contrary, then, this...presents us with no epistemic response to the skeptic at all. (Pritchard 2005: 207)

The general complaint is this: we all recognize that there are good practical reasons to avoid skepticism, but this provides us with no good epistemic reasons to dismiss the skeptic. The impractical consequences of skepticism are, allegedly, irrelevant to its truth.

For the most part, I agree that a theory is not rendered implausible simply because accepting it would be inconvenient, impractical, or bad for us in some way. Nevertheless, I think there is an important sense in which the impractical consequences of skepticism are relevant to evaluating its truth. In fact, I hope to convince you that skepticism is implausible because it is impractical (in a particular way). If I am right, then at least one version of pragmatic anti-skepticism is a reasonable philosophical view.

\section{The New Apraxia Objection}


One of the most famous and historically important objections to skepticism is the problem of how to live with skepticism. This is called the "problem of apraxia". Historically, the problem of apraxia was understood as the problem of how to live as a skeptic, that is, as someone who suspends judgment in belief. This objection was targeted primarily at the ancient Pyrrhonists, who recommended that we suspend judgment to avoid error. A wellknown worry for this view is that it amounts to a kind of intellectual suicide. The formation of beliefs is a basic aspect of human life, and it is unclear whether we can live an ordinary life without belief. Indeed, belief formation may be necessary for our survival, in which case skepticism would be more than intellectual suicide.

The merits of the apraxia objection need not concern us. I am primarily interested in contemporary (i.e. post-Cartesian) skepticism, not ancient pyrrhonism. Contemporary skeptics rarely argue that we should suspend judgment in belief. Rather, their target is knowledge (or justification). ${ }^{2}$

Contemporary skepticism comes in at least two forms. First, the skeptic may argue that knowledge requires one to meet an incredibly high epistemic standard. In particular, knowledge requires the highest possible degree of justification (evidence, probability, warrant, reliability); viz., justification that guarantees the truth of the claim believed. ${ }^{3}$ Second, the skeptic may not speak of "standards" for knowledge but instead argue that we simply have no evidence or justification to support the belief that things are the way they appear (as opposed to some radically skeptical way). In both cases, the skeptic tends to argue that we know nothing, or almost nothing, about the world around us because we cannot rule out the possibility that we are systematically deceived. For example, I do not know that I have hands because I do not know that I am not a brain in a vat artificially stimulated to have these impressions. A key difference between these views, however, is that the second type of skeptic is also skeptical about justified belief.

In what follows, I will focus primarily on skepticism about knowledge. This view is widely discussed in contemporary epistemology. ${ }^{4}$ I think my pragmatic account can be adapted to 
provide an argument against skepticism about justification, but I will set aside this view for ease of exposition (although I will briefly discuss it in section 7.4).

Unlike the Pyrrhonists, contemporary skeptics do not recommend the suspension of judgment; thus, they will not face the problem of being unable to act without belief. As Descartes observes, the skeptics of his day did not extend their doubts to "the actions of life." Why, then, have I brought up the apraxia objection? It is because the question of how to live with skepticism, even in its contemporary form, is still an important one for philosophers to consider. In this paper, I want to outline a substantially modified version of the apraxia objection. I will not argue that skepticism is unlivable because we cannot act without belief (the traditional apraxia objection). Rather, I will argue that skepticism is implausible because it goes against the very purpose of epistemic evaluation. I call this the new apraxia objection.

\section{The Practical Role(s) of Knowledge}

An increasingly popular idea in epistemology is that an adequate theory of knowledge should fit plausible assumptions about the point or purposes of the concept of knowledge. We may regard this as a "functionalist turn" in epistemology. The idea, put roughly, is that we have a practice of epistemic evaluation to serve certain purposes; thus, our strategy should be to use the role (or roles) of the concept of knowledge as an adequacy constraint on the theory of knowledge. We find this idea in Edward Craig's groundbreaking work, Knowledge and the State of Nature, from which many epistemologists now draw inspiration. ${ }^{5}$ Instead of analyzing knowledge into necessary and sufficient conditions, Craig recommends that we investigate the concept of knowledge by asking, first, what it does for us (what its role is) and then, second, what a concept having that role would look like (what conditions would govern its application). The general thought is that we come to understand the nature and value of knowledge by asking about the practical function of the concept of knowledge.

This contrasts with the usual focus in epistemology. Scholars investigating the nature of knowledge and the plausibility of skepticism have tended to focus on whether knowledge 
(or 'knows') requires agents to satisfy the skeptic's demanding standards. Largely absent from this debate, however, has been any reflection on why knowledge (or 'knows') would come equipped with such standards. I want to reconsider the merits of skepticism in light of this question. I will argue that skepticism is unable to underwrite the primary roles that our knowledge concept plays in epistemic evaluation. This is because skepticism has no connection with the practical circumstances that explain why we speak of knowing in the first place. On these grounds, I will argue that skepticism should be regarded as an implausible theory of knowledge.

But first I must say more about what exactly the function of epistemic evaluation is supposed to be. If knowledge is valuable because it serves an important practical role in human life, just what is this role (or what are these roles)? I will explore the four most popular accounts and I will use these to explain why skepticism ought to be rejected on pragmatic grounds.

\section{The Informant-Flagging Function}

According to Craig (1990), the primary function of the concept of knowledge is to identify reliable informants. Elsewhere I have provided a book-length defense of this idea (see Hannon 2019). For the sake of brevity, I won't recapitulate the details of this view here. Rather, I will outline a small number of highly plausible and easily stated assumptions that support Craig's hypothesis.

The first assumption is that human beings need true beliefs about their environment to successfully guide their actions. ${ }^{6}$ The second assumption, which derives from the first, is that humans require sources of information that will lead to true beliefs. The third assumption, which is strongly supported by recent work in the epistemology of testimony, is that most of our information about the world comes to us from the testimony of others (Lackey and Sosa 2006). If you want to find out whether $p$, then asking someone reliable is often the easiest and most efficient way to do so. The fourth assumption is that informants will typically vary in terms of their reliability. On almost any issue, some people are more likely than others to be right. Consequently, we all have an interest in evaluating the 
epistemic quality of our informants. We want to distinguish the people on whom we should rely from those we shouldn't rely on. According to Craig, our practice of epistemic evaluation is a response to this need. More specifically, the concept of knowledge is used as a marker for sufficiently reliable informants.

This disarmingly simple hypothesis explains why we tend to value knowers: they help us acquire reliable information. It also explains why the concept of knowledge is valuable: it plays an important-perhaps indispensable-role in our conceptual repertoire; in particular, it allows us to identify reliable sources of information. In this way, our practice of epistemic evaluation contributes to human survival, cooperation, and prosperity.

Does this functionalist story facilitate a pragmatic response to the skeptic? I believe it does.

Inquirers want reliable information on which to base their beliefs and actions. Following David Henderson (2009), let's calls this "actionable information". We each want actionable information to help satisfy our other needs and interest. However, our desire for information extends beyond our own immediate context. Although we often want information "here and now", it is also in our collective interest to pool information and share it with members of our community. Thus, we tend to assess the reliability of informants not just for ourselves but for others, too, since this allows us to store reliable information while it is available-without knowing when, why, or under what circumstances it may be needed. This requires each of us to evaluate the adequacy of informants for people and purposes outside our immediate context. In short, we need to share information and identify good informants in general. ${ }^{7}$ When we attribute knowledge to someone, we are thereby certifying the agent's epistemic position as good enough for the community at large.

But how good is "good enough"? 
This is a difficult theoretical problem. ${ }^{8}$ Thankfully, we needn't get into the details of determining precisely where this threshold for knowledge is set. For our purposes, it will suffice to acknowledge that this standard cannot be too low nor can it be too high.

If it were too easy to qualify as a knower, then our concept of knowledge couldn't play the role of identifying individuals who are reliable enough for a wide range of potential inquirers. As Craig puts it:

a practice develops of setting the standard very high, so that whatever turns, for others, on getting the truth about $p$, we need not fear reproach if they follow our recommendation... In recommending an informant to you I am indeed implying that the likelihood of his being right is as great as your concerns require. (1990: 94)

In other words, the informant-flagging function puts upward pressure on the standards required to qualify as a knower. To count as a knower, an informant must be "someone with a very high degree of reliability, someone who is very likely to be right" (Craig 1990: 91).

But the standard cannot be too high, either. Why not? Because demanding infallibility from fallible humans would undermine the very point of having a concept of knowledge. On Craig's view, we engage in epistemic evaluation to flag informants who can provide us with reliable information, but if we were to insist on the highest level of justification (i.e. the level demanded by the skeptic), then we would exclude a vast number of inquirers who are perfectly reliable for everyday purposes. ${ }^{9}$

An example will illustrate this idea. A Student and a Birdwatcher are both looking at a goldfinch. ${ }^{10}$ Each attempts to form beliefs on the basis of their experience. The Student has very limited knowledge and is unable to rule out the possibility that the bird is a woodpecker. The Birdwatcher, by contrast, can easily tell the difference between a woodpecker and a goldfinch. In fact, the Birdwatcher often wins birdwatching contests because he is so highly skilled at distinguishing various birds. Nevertheless, the Student and 
the Birdwatcher are both unable to tell whether they have been recently envatted and are merely looking at a vat-image of a goldfinch.

Although both the Student and the Birdwatcher are unable to rule out radical skeptical scenarios, the Birdwatcher is still more discriminating than the Student. This illustrates that we may still draw distinctions that we tend to care about even though neither the Student nor the Birdwatcher can eliminate skeptical worries. As Jonathan Schaffer says, their discriminatory range differs and "one's epistemic standing is based on one's discriminatory range" (2004: 152).

The skeptic will deny that the Birdwatcher knows that the animal is a goldfinch. But why would knowledge require us to meet the skeptic's demands? To insist upon skeptical requirements would exclude a vast number of informants who are perfectly suitable for the purposes of many, perhaps most, inquirers. By withholding a knowledge ascription, we would suggest to others that these perfectly reliable informants do not have sufficiently good information on which others can base their beliefs and actions. Yet there is a clear benefit to treating individuals as good informants if they are likely enough to be correct for everyday purposes: we do not always require our informants to have the highest quality epistemic position. Indeed, almost no inquirer is concerned, in daily life, with finding an informant who can distinguish radical skeptical scenarios from non-skeptical scenarios. Presumably this is because no such people exist. We are all epistemically limited in this way, so there can be no practical advantage in seeking out informants who are able to do the impossible.

Here's another example. Suppose I am inquiring into the whereabouts of my cat, Garfield. It might be that neither you nor I (nor anyone else) can rule out the possibility that we are brains in vats, but your epistemic position might still be better than mine in various ways. Perhaps you have already thoroughly checked the kitchen while I have not (or at least the nearest envatted equivalent of doing this). Or perhaps my wife told you that Garfield is at the vet. These are distinctions that we care about, but they get lost if too many possibilities are selected as ones we must rule out. 
This pragmatic approach helps shed light on why skepticism is implausible. The concept of knowledge is rooted in the social-epistemological need for pooling and sharing information, which generates a need to identify informants who can provide us with reliable information. The skeptical result runs against this approach because it would frustrate our communal epistemic practices. To deny knowledge to a potential informant would suggest that they are not in a strong enough epistemic position to appropriately contribute to the stock of information on which others can draw for various projects. The problem with skeptical standards is that they restrict us to recommending informants who are infallible, but in doing so we can recommend no informants at all (or hardly any). We have no use for such a concept.

So far I have followed Craig by arguing that the concept of knowledge is rooted in our fundamental need to identify reliable informants. But why think knowledge serves only this role?

Elsewhere I have argued that the informant-flagging function is the primary function of our knowledge concept, but I will not argue for that view here. Rather, I will briefly consider three additional accounts of the purpose of knowledge and I will argue that skepticism is also incompatible with each of these hypotheses.

\section{The Inquiry-Stopping Function}

Another popular view is that inquiry appropriately ends at knowledge. As Jonathan Kvanvig (2009: 344) writes, "When you conceive of yourself as knowing a given claim, you will be puzzled by any counsel to investigate the matter further." For example, we may stop inquiring into whether the bank is open tomorrow when we come to know that it is open tomorrow (DeRose 2009). Knowledge settles the question. ${ }^{11}$

We can motivate this view in the following way. We start with the assumption that, as inquirers, we seek reliable information on which to base our actions. However, the process of inquiry is potentially open-ended. For example, what does it take to know that David 
Foster Wallace is the author of Infinite Jest? Would it suffice to ask someone reliable? Must I see the book myself? Must I confirm with the publisher that the author's name was correctly printed on the book? Must I investigate whether the novel was actually ghostwritten? Must I know that I am not a brain in a vat? Inquiry can be thought of as a process of ruling out various possibilities; however, it is almost always possible to continue one's inquiry (logical possibilities are endless). Thus, we need a point at which people can reasonably terminate inquiry. According to Kvanvig, this stopping point is cognitively valuable because it satisfies one of the platitudes about the functional roles of knowledge: it signals the point of legitimate inquiry closure (2009: 344).

Let's assume that we need to signal when inquiry has gone on long enough. How long is that? It is when one has knowledge, according to this view. But what is required for knowledge? By reflecting on the practical role of epistemic evaluation, we again get crucial leverage against the skeptic.

The claim that knowledge licenses the closure of inquiry makes sense only if we are fallibilists. If knowledge demanded too much, inquiry would go on endlessly. After all, inquiry has no natural stopping point because there are always further conceivable but uneliminated possibilities of error. We therefore need an explanation for why inquiry would demand less than infallibility (or perfect reliability, certainty, the ability to rule out brains in vats, etc.). The most plausible explanation, to my mind, is that continuing to inquire beyond a certain point would be impractical: it would commit us to paying higher informational costs that are not worth the lessened risk of being wrong. Indeed, the skeptic seems to demand that we satisfy conditions that are impossible for any fallible creature to satisfy. But the circumstances of daily life do not demand that our chances of being wrong are absolutely zero (as argued in the previous section). Thus, the best way to make sense of the idea that inquiry appropriately ends at knowledge is by embracing fallibilism and denying skepticism.

\section{Knowledge, Assertion, and Practical Reasoning}


Let's briefly consider two more ways in which the impractical consequences of skepticism undermine its plausibility. I will then discuss several objections to my pragmatic antiskeptical view.

Suppose, first, that you are in a good enough epistemic position to assert that $p$ if (and perhaps only if) you know that $p .{ }^{12}$ If skepticism were true, then assertions could almost never be epistemically warranted (at least not without some probability qualification). But such a result seems obviously intolerable from a practical standpoint because we often have urgent needs for communicating information. Thus, it makes more sense to suppose that knowledge is the norm of assertion only if skepticism is false. Likewise, assume that you are in a good enough epistemic position to rely on $\mathrm{p}$ in practical reasoning if (and perhaps only if) you know that $p .^{13}$ If skepticism were true, then your justification would almost never provide a sufficient basis for practical reasoning. This is problematic because we are still faced with the unavoidable need to act; thus, there is practical pressure to think knowledge is the relevant norm only if skepticism is false.

I am not claiming that the knowledge norms are logically inconsistent with skepticism. We could in principle accept the knowledge norms but abstain from engaging in any assertions and practical reasoning. ${ }^{14}$ My claim is that the intuitive connections between knowledge, assertion, and practical reasoning are practically incoherent (see Hawthorne 2004: 133-4). In other words, it is a matter of practical necessity that we do need to assert and reason practically in our everyday life in order to survive and pursue our aims. Skepticism would render these activities impossible unless we constantly violated the epistemic norms governing these practices.

In summary, the skeptic invites us to abandon the very purpose (or purposes) of our practice of epistemic evaluation. By taking a pragmatist view, it becomes difficult to see how the skeptical demand for infallibility would serve fallible creatures in everyday life. When the requirements for knowledge are too demanding, it frustrates our communal epistemic practices and is antithetical to the point of epistemic evaluation. Pragmatism can 
help us resist skepticism by explaining why there is downward pressure on the epistemic standards for knowledge.

I doubt that what I have said completely rules out the possibility of skepticism. After all, there is nothing logically inconsistent with the skeptic's conclusion. Perhaps a better way to frame my argument, then, is in terms of a dilemma for the skeptic. ${ }^{15}$ Either the purpose of knowledge is such that it rules out skepticism, or else knowledge is itself a useless and uninteresting concept. So even if skepticism were true, our inability to identify a practical function for knowledge would make it unclear why we should care much about the absence of knowledge.

\section{Objections and Replies}

I have been arguing that skepticism is incompatible with the function of epistemic evaluation. However, one might criticize my argument in several ways. Below I consider some objections to my view.

\subsection{Are the Functions of Knowledge That I Have Identified the Right Ones?}

I have provided four explanations for why skepticism is incompatible with the practical role of knowledge: the informant-flagging function, the inquiry-stopping function, the need for an epistemic norm governing warranted assertion, and the need for an epistemic norm governing practical reasoning. But these hypotheses are not uncontroversial; objections have been made against each of them. Moreover, this list may not be exhaustive. Beyond the roles I have identified, scholars have claimed that knowledge is connected to activities like: distinguishing blameworthy and blameless behavior (Beebe 2012), providing assurance (Lawlor 2013), countering doubts (Rysiew 2001), and indicating that one is certain (BonJour 2010). This plurality may lead us to wonder whether some additional role (or roles) will better fit with skepticism than fallibilism.

\section{Replies}

The four functional accounts I have discussed are, of course, not the only ones availablenor are they free from criticism. However, they are the most popular and widely discussed 
accounts of the functional role of knowledge. Thus, any other hypothesis I might have considered would have been even more controversial. Further, I have elsewhere explored a broader range of hypotheses about the function of epistemic evaluation, and I have argued that all these hypotheses tend to support fallibilism over infallibilism. ${ }^{16}$ In addition, it is a weak objection to simply point out there might be a hypothesis about the function of knowledge that better fits with skepticism. Surely this claim needs to be argued for. Finally, any skeptic-friendly hypothesis would have to be more compelling than the considerations I have marshalled against skepticism; otherwise my own view would still be more plausible on balance.

\subsection{Skeptical Standards Are Just a Brute Fact about Knowledge}

I have argued that skepticism is implausible because it contradicts the purpose of epistemic evaluation. In response, one might claim it is simply a brute fact about knowledge that it requires us to meet the skeptic's standards. Robert Pasnau makes this point: "If anyone wonders why the standards for knowledge must be so high, the response is just that this is what the word means" (2015: 260). Although Pasnau refers to the meaning of the word 'knowledge', one might also argue that skeptical standards are simply a fact about knowledge.

\section{Replies}

The "brute fact view" is unsatisfying for three reasons.

First, it simply disregards what I take to be an important criterion for a theory of knowledge, namely, that it provides a plausible explanation for why knowledge is equipped with the features that it has. There is something deeply unsatisfying with an account that leaves this question unanswered. Indeed, Panayot Butchvarov considers this to be the most characteristic symptom of the inadequacy of traditional accounts of knowledge (1970: 256). My own view, in contrast, provides several explanations for why knowledge requires fallible rather than infallible justification. 
Second, the "brute fact view" about the meaning of the word "knowledge' is highly implausible. It seems to assume that our words come to us pre-programmed with specific meanings, as though they were delivered from on high, rather than designed to serve some purpose(s) for the people who use them. Further, the brute fact view about knowledge (rather than the word 'knowledge') seems to implicitly presume that knowledge is a natural kind. This is a highly contentious view. While Hilary Kornblith (2002) has carefully articulated this idea, few epistemologists are convinced that knowledge is a natural kind. ${ }^{17} \mathrm{~A}$ more plausible view, I think, is that knowledge is a social or artifactual kind; it is not something we find in the world, like rocks and water, but rather is something we impose on it. ${ }^{18}$ Accordingly, the identity conditions for knowledge are intertwined with human interests and intentions. This aligns with the functionalist account of knowledge that I have been defending in this paper.

Third, even if knowledge were a natural kind, this idea still faces a problem. As Hume, Nietzsche, and other genealogically-inclined philosophers make clear, we take our use of concepts to have a contingent human history. Thus, we still need an explanation for why we would ever have invented or adopted a particular concept in recognizably naturalistic terms. So even if knowledge were a natural kind, it would still be hard to explain why humans have adopted and employed it as we have if we could not assign any practical value to it.

\subsection{All I Have Shown Is That It Is Useful to Say That People Have Knowledge}

The skeptic may resist my argument by drawing a distinction between the conditions that must be satisfied to appropriately say that somebody has knowledge, on the one hand, and the true conditions for knowledge, on the other. As Paul Grice (1989) made clear, all the conditions for warranted assertion can be met even though what is said is not literally true. With this familiar distinction in hand, the skeptic may argue as follows: the practical factors that I have mentioned are what determine the conditions for appropriately ascribing knowledge, but knowledge itself is actually subject to skeptical requirements.

We find this argument in Barry Stroud's book, The Significance of Philosophical Skepticism. He maintains that it is perfectly appropriate to credit people with knowledge in daily life, 
but he also says there really is no such thing as knowledge (or at least a lot less than we suppose). Peter Unger (1975) defends a similar view. He argues that knowledge is an 'absolute term' in the sense that it requires us to meet the highest possible standard: absolute certainty. This leads to skepticism. But Unger nevertheless maintains that it is perfectly acceptable to say that we know things in the context of ordinary life.

The skeptic may supplement this view with a pragmatic explanation for the assertability of knowledge. This enables her to explain our intuitions about the acceptability of ordinary knowledge ascriptions. For example, the skeptic may claim that it is unnecessarily fussy to insist that a belief isn't knowledge when the believer is close enough to meeting the ideal standard. Alternatively, it could be that people reasonably regard their justification for a belief as conclusive when in fact deeper philosophical reflection reveals it is not. Or perhaps one who claims to know that $p$ is really making a conditional or elliptical claim, namely: one knows $\mathrm{p}$ assuming that some alternative possibilities which are not worth taking seriously are indeed false. ${ }^{19}$ These are just a few examples. I mention them simply to illustrate that the skeptic has several ways to explain why we routinely (but falsely) speak of knowing.

Stroud provides a closely related explanation. He says that "practical exigency" prevents us from applying skeptical standards in real-life situations:

There is a single conception of knowledge at work both in everyday life and in the philosophical investigation of human knowledge, but that conception operates in everyday life under the constraints of social practice and the exigencies of action, co-operation and communication. The practical social purposes served by our assertions and claims to know things in everyday life explain why we are normally satisfied with less than what, with detachment, we can be brought to acknowledge are the full conditions of knowledge. From the detached point of view-when only the question of whether we know is at issue-our interests and assertions in everyday life are seen as restricted in certain ways. (Stroud 1984: 71)

In other words, we recognize that for practical purposes we cannot entertain skeptical challenges, since we have urgent needs for communicating information and it would be too 
cumbersome to couch virtually all our assertions in probabilistic terms. We therefore ignore the skeptical requirements for knowledge in daily life.

Supposing this line of reasoning is correct, skepticism would no longer risk practical or intellectual disaster, for it would leave untouched our ordinary practice of epistemic evaluation. On this view, we are pragmatically warranted in continuing to attribute knowledge to others and ourselves, even though nobody, strictly speaking, knows anything. I will call this view "pragmatic skepticism". ${ }^{20}$ The pragmatic skeptic claims that our ordinary knowledge claims are for the most part appropriate and reasonable. In other words, our ordinary practice of epistemic evaluation is perfectly in order and, thus, skepticism has no impractical consequences.

Pragmatic skepticism creates a special problem for my view (which I've dubbed pragmatic anti-skepticism). Both the pragmatic skeptic and the pragmatic anti-skeptic appeal to practical considerations to avoid the potentially disastrous consequences of skepticism; however, the pragmatic skeptic uses practical considerations to explain the plausibility of skepticism, while the pragmatic anti-skeptic uses these same considerations to explain the implausibility of skepticism. Does this mean that practical factors cannot help to adjudicate the dispute between the skeptics and their rivals?

\section{Replies}

Pragmatic skepticism faces three initial objections. First, it runs the risk of idleness. Berislav Marušić (2010) raises this objection. He writes, "If a skeptic grants that we should continue claiming that we know things, engaging in enquiries, and relying on the results of science, then it seems that she hasn't taken the skeptical conclusion seriously" (2010: 61). I am inclined to agree. One has not genuinely become a skeptic if one is happy to leave our practice of epistemic evaluation totally untouched by the truth of skepticism. Second, if skepticism were not worrying or had no negative consequences, it would be surprising why so many scholars have dedicated their efforts to replying to skeptical challenges. Third, one could respond to the pragmatic skeptic by appealing to semantic ascent. We could argue 
that the extension of 'know' must be non-skeptical in order to serve its role. In this case, one's investigation would be about the use of the word 'knows' and not about knowledge. ${ }^{21}$

But I want to make a different, and I think deeper, objection to pragmatic skepticism. I will argue that this view is not well motivated because it fails to explain the plausibility of skeptical standards for knowledge. Let me elaborate.

The pragmatic skeptic says the requirements we must satisfy to merit a knowledge ascription are very different from the standards required for knowledge-we often satisfy the former, but we rarely, if ever, satisfy the latter. The pragmatic skeptic also recognizes the important practical role that knowledge ascriptions play in ordinary life. However, these practical considerations are said to have no bearing on whether one knows. This creates a puzzle. Why would it be that speaking of 'knowing' plays vital roles in everyday life while the actual standards for knowledge are radically out of touch with these roles? In other words, what point would there be in a knowledge concept that is equipped with skeptical standards? The pragmatic anti-skeptic has a plausible story to tell about why our knowledge concept is shaped a particular way. The skeptic, in contrast, has no such story. Skepticism leaves unexplained why the assertability conditions for 'know' would be sensitive to practical exigencies while the truth conditions for knowledge would be isolated from, and unaffected by, such pragmatic considerations. Why would the conditions for knowing be isolated from the utility of this practice? In short, why keep two sets of books?

Consider the following argument by Laurence BonJour. He admits that meeting the skeptic's demands is "obviously intolerable from a practical standpoint" (2010: 74). Yet he also claims that knowledge is the norm governing assertion and practical reasoning. This view is perplexing. On the one hand, BonJour recognizes that there is "practical pressure in the direction of reasoning from and acting upon claims whose justification does not fully meet the standard for knowledge" (2010: 75). On the other hand, he admits that assertions can almost never properly be made and practical reasoning would be paralyzed, given skeptical requirements. BonJour thus concludes that we must, for practical purposes, make unqualified assertions and act upon claims even when "this is not really (fully) warranted by 
the epistemic situation" (2010: 74). But if the relevant epistemic norm would paralyze action and render almost all assertions improper, why should we think that the norm governing these activities is knowledge (in the skeptic's sense)? What explanation could be given for-and what purpose could possibly be served by-having an epistemic norm to govern these highly practical activities when that very same norm threatens to render these activities impossible? It makes sense to regard knowledge as the relevant norm only if we adopt a fallibilist conception of knowledge.

The general complaint against pragmatic skepticism is that it leaves mysterious why knowledge would be equipped with skeptical requirements in the first place. The pragmatic skeptic is able to provide an explanation for why we ordinarily say that people know things (thereby making an important advance on less sophisticated forms of skepticism), but their view has no connection to any plausible hypothesis about the point of epistemic assessment. As suggested earlier, a plausible theory of knowledge must be true to facts about the purpose for which this epistemically evaluative practice exists. Thus, what's wrong with skepticism is not that it lacks fidelity to our ordinary practice of knowledge attribution (the pragmatic skeptic can explain that away); the problem, rather, is that it lacks fidelity to the very purpose (or purposes) of speaking of knowing.

I now want to consider a related, but importantly different, objection to my view. Instead of providing a pragmatic explanation for why we speak of knowing, the skeptic might instead argue that skepticism itself can be grounded in practical factors. I consider this idea below.

\subsection{Knowledge as a Regulative Ideal}

Perhaps some practical considerations do favor skepticism over fallibilism. This is different from the view outlined in the previous section. According to the previous view, practical factors explain why it is reasonable or appropriate to attribute knowledge to people. I complained that this view gives no plausible story for why knowledge (or our concept of knowledge) would be equipped with skeptical standards. But perhaps there are practical factors that push in the direction of skepticism. 
What practical favors might these be? A promising idea is that infallibility provides us with a regulative ideal. According to this view, the concept of knowledge characterizes an ideal cognitive state or situation. We will rarely achieve this ideal, but it nonetheless provides us with a useful goal to which we should aspire. In this way, knowledge is not very different from other commonly accepted ideals, such as moral or aesthetic ideals. For example, no one will ever be perfectly moral, but we should still try to be as moral as possible. Similarly, we will never fully escape our own biases, but we should try to be unbiased. These regulative ideals describe states of affairs that are highly valuable and desirable, even though they are rarely, if ever, achieved. Still, we may enlist these ideals as benchmarks worth aiming at.

I will call the defender of this view the "practical ideals skeptic". This skeptic will agree that infallible knowledge represents an unachievable standard, but she will also argue that unachievable standards can play important practical roles in human life. Thus, the fact that we know nothing or almost nothing does not undermine the practical role of (infallible) knowledge-or so the objection goes.

\section{Replies}

I will not take issue with the claim that epistemic ideals are important and worth pursuing. This seems uncontroversial. What is controversial, however, is whether the practical value of epistemic ideals lends any support to skepticism. Below I provide two reasons to doubt this view. First, the practical value of epistemic ideals presupposes that we can approach or approximate the relevant ideal, but this assumption runs against the radical skeptic's argument. Second, the fact that it is useful to aspire towards some cognitive ideal gives us little reason to think the relevant ideal is knowledge (or knowing).

Let's suppose that knowledge is an ideal cognitive state that provides us with a benchmark worth aspiring to. To have practical value, this cognitive ideal must be approachable to some degree. If we were unable to make any progress towards our ideal goal, then aspiring to it would surely be pointless. For example, if it were impossible for humans to diminish their biases to any extent, then striving to be unbiased would have no practical value. 
Similarly, if it were impossible for humans to morally better themselves to any degree, then striving for moral perfection would be pointless. Thus, "practical ideals skepticism" must assume that our cognitive ideals are approachable.

But many skeptics reject this assumption.

Hilary Kornblith (2000) draws a useful distinction between the "full-blooded skeptic" and the "high-standards skeptic". The full-blooded skeptic claims that "we are no more justified in believing that there is an external world than that there isn't," and that we "have no degree of justification whatever for [our] claims about the external world" (2000: 26). In contrast, the high-standards skeptic is perfectly willing to grant there are differences in degree of justification that people have for their various beliefs; she simply denies that we ever reach some very high standard required for knowledge.

With this distinction in hand, it becomes clear that "practical ideals skepticism" is a version of high-standards skepticism. The practical ideals skeptic assumes we are able to approximate or approach our epistemic ideals, whereas the full-blooded skeptic denies the possibility of such epistemic success. Is this a problem for the practical ideals skeptic?

According to many philosophers, high-standards skepticism is not a very interesting or threatening philosophical position. As soon as we admit that some beliefs are epistemically better than others, skepticism loses its teeth. As Pasnau puts it, "If that is all that is at stake in the quarrel over skepticism, then who cares?" (2015: 260). Similarly, Kornblith claims that high-standards skepticism is "a wholly trivial and uninteresting position" (2000: 27). Wright also finds high-standards skepticism to be toothless:

We can live with the concession that we do not, strictly, know some of the things we believed ourselves to know, provided we can retain the thought that we are fully justified in accepting them...What is not tolerable is the thesis that...we never actually attain to genuinely justified opinion: that no real distinction corresponds to that which we are accustomed to draw between grounded and ungrounded beliefs. (1991: 88) 
Thus, appealing to the practical role of epistemic ideals might drain skepticism of its significance. Practical ideals skepticism is incompatible with full-blooded skepticism, and yet it is the full-blooded skeptic who is allegedly making "a historically important and philosophically interesting claim" (Kornblith 2000: 27). According to Wright (1991), it is a constraint on responding to skepticism that we do not rely on the assumption that our beliefs may be more or less justified.

Admittedly, some philosophers find high-standards skepticism to be interesting and worrying. As DeRose (2017) observes, the skepticism of Descartes' First Meditation is actually a form of high-standards skepticism. ${ }^{22}$ Further, many contemporary epistemologists seem to defend high-standards skepticism, not full-blooded skepticism; I am here thinking of Unger (1975), Stroud (1984), Davis (2007), and BonJour (2010). ${ }^{23}$

But even if we set aside the question of whether high-standards skepticism is interesting, threatening, or historically significant, there is a deeper problem for this view. Once we grant that our beliefs can be more or less justified, it becomes unclear why we should accept the skeptic's claim that our ideal cognitive state is that of knowledge. Why not hold the following view instead: (a) there is some cognitive state indicative of "full cognitive success", (b) this ideal has practical value, and yet (c) this ideal is not adequately characterized as knowledge? This is my second line of response to the "practical ideals skeptic". I'll elaborate below.

According to BonJour, knowledge is a "supremely valuable and desirable cognitive state" indicative of "full cognitive success" (2010: 58). To make sense of the value of knowledge, BonJour maintains that knowledge requires "the highest possible degree of justification: justification that is conclusive, that guarantees the truth of the claim that is believed" (ibid: 59). Why think knowledge requires infallible justification? According to BonJour, it makes sense to say that knowledge demands the highest level of justification because this would guarantee the truth of our belief, and thus our belief's aim is achieved. ${ }^{24}$ Complete cognitive 
success is achieved only when our justification is sufficient to establish completely that our belief is true.

Fair enough. But is it natural or reasonable to identify the situation of such complete success as one of knowledge (or knowing)? BonJour seems to think so, but this claim relies crucially on the assumption that knowledge is "a supremely valuable and desirable cognitive state, one whose possession marks the difference between full cognitive success and at least some degree of cognitive failure: knowledge is the epistemic summum bonum" (2010: 58). Why give knowledge this lofty status? BonJour provides the following explanation: skepticism is intellectually threatening because knowledge has this exalted status (ibid). But this seems rather weak justification in the context of the skeptical puzzle. Wouldn't skepticism be more threatening if it endangered something we take ourselves to possess in ordinary life, not some ideal we never achieve? Thus, it is implausible to think our ordinary concept of knowledge is characterizing this ideal. It is more plausible to regard this cognitive ideal as demanding more than knowledge (or perhaps as characterizing a special form of knowledge).

In a recent paper titled "Idealized Epistemology", Robert Pasnau makes this point quite convincingly. He argues that Aristotle, Descartes, and many other historical philosophers were primarily interested in the study of epistemic ideals, but he also says our ordinary concept of knowledge does not identify this ideal epistemic state. In his discussion of Aristotle, for example, Pasnau says that Aristotle characterizes his subject matter as haplos epistêmê, which is an ideal epistemic state. Although Pasnau translates this as "unconditional or unqualified knowledge" (2013: 994), he directly contrasts this notion with "the ordinary sorts of knowledge that human beings regularly do possess" (ibid). Pasnau goes on to say that Aristotle and Descartes are "offering not a theory of 'knowledge'... but an account of the ideal limit of human inquiry" (2013: 995, emphasis mine). In other words, the ideal limit of human inquiry is contrasted with knowledge.

Thus, there is little reason to think our everyday concept of knowledge is used to mark out this idealized epistemic state. This creates a problem for the skeptic. The skeptic was 
supposed to show that we lack knowledge. But if knowledge is not the epistemic ideal, then our inability to achieve this cognitive state is no threat to what we know. The skeptic may wish to affix the label "knowledge" to this epistemic ideal, but this would trivialize their view. Although no one would "know" anything, according to the skeptic's definition, we would continue to know things according to the ordinary notion of knowledge. Further, we have a good reason not to replace the ordinary notion with the skeptic's: it wouldn't serve any practical purpose in epistemic evaluation.

So far I have only considered the practical role of epistemic ideals. Perhaps there are other practical factors that could push us toward skepticism. From the point of view of error avoidance, for example, radical doubt seems optimal. But we must balance our desire to avoid error with the need to acquire true beliefs, and I doubt that any such epistemic policy would favor skeptical standards. Indeed, we would need an obsessional interest in avoiding error at the expense of acquiring truth. Alternatively, one might argue that infallible standards are instrumentally valuable because they cultivate intellectual humility and openmindedness. I do not have space to discuss all these possible views. While my exploration of the practical grounds for skepticism has not been exhaustive, I find it reasonable to conclude that the search for practical factors that would push us into the arms of the skeptic is unpromising. I doubt that practical motives could lead us to prefer imposing requirements that would keep out falsehoods by rejecting everything.

\section{Conclusion}

Can we live with the results of skepticism? If not, does this have any bearing on the truth of the skeptic's view?

Pragmatic resolutions to skepticism are often dismissed. Although the consequences of skepticism might be practically or intellectually disastrous, this fact is believed to have little, if any, bearing on the truth of skepticism. I have argued, however, that skepticism is implausible because it is impractical. More specifically, skepticism is implausible because it goes against the point of epistemic evaluation. When we consider epistemic evaluation in terms of its function, we realize that skepticism would prevent us from reasonably ending 
our inquiries, thwart our ability to identify informants on whom we can rely for actionable information, render almost all of our assertions improper, and threaten to paralyze action. This provides us with an adequate reason to think that knowledge isn't equipped with skeptical standards.

Acknowledgements. Thanks to Bryan Frances, Max Hayward, Lisa Miracchi, Jon Robson, Simon-Pierre Chevarie-Cossette, and Christos Kyriacou for helpful comments on a draft of this paper. 


\section{Works Cited}

Aikin, S. and T. Dabay, 2018. "Pragmatist Anti-Skepticism: At What Price?" In K. McCain and T. Poston (eds.), The Mystery of Skepticism. Brill.

Austin, J. L. 1979. Philosophical Papers, 3rd edition. Oxford University Press.

Beebe, J. 2012. "Social Functions of Knowledge Attributions." In J. Brown and M. Gerken (eds.), Knowledge Ascriptions. Oxford University Press.

BonJour, L. 2010. “The Myth of Knowledge." Philosophical Perspectives 24 (1): 57-83.

Butchvarov, P. 1970. The Concept of Knowledge. Northwestern University Press.

Craig, E. J. 1990. Knowledge and the State of Nature. Oxford University Press.

Davis, W. 2007. "Knowledge Claims and Context: Loose Use." Philosophical Studies 132 (3): 395-438.

DeRose, K. 2017. The Appearance of Ignorance. Oxford University Press.

DeRose, K. 2009. The Case for Contextualism. Oxford University Press.

Dogramaci, S. 2019. "The Ordinary Language Argument Against Skepticism-Pragmatized."

Philosophical Studies 176 (4): 879-896.

Fricker, M. 2007. Epistemic Injustice. Oxford University Press.

Gardiner, G. 2015. "Teleologies and the Methodology of Epistemology." In D. Henderson and J. Greco (eds.), Epistemic Evaluation: Purposeful Epistemology. Oxford University Press. Greco, D. 2012. “The Impossibility of Skepticism." Philosophical Review 121 (3): 317-358. Greco, J. 2008. What's Wrong with Contextualism? Philosophical Quarterly 58 (232): 416436.

Grice, H. P. 1989. Studies in the Way of Words. Harvard University Press. Hannon, M. 2019. What's the Point of Knowledge? Oxford University Press. Hannon, M. 2017. “A Solution to Knowledge's Threshold Problem." Philosophical Studies 174 (3): 607-629. Hawthorne, J. 2004. Knowledge and Lotteries. Oxford University Press. 
Hawthorne, J. and J. Stanley. 2008. "Knowledge and Action." Journal of Philosophy 105 (10): 571-590.

Hazlett, A. 2014. A Critical Introduction to Skepticism. Bloomsbury.

Henderson, D. 2009. “Motivated Contextualism.” Philosophical Studies 142 (1): 119-131.

Hetherington, S. 2006. “Knowledge's Boundary Problem." Synthese 150 (1): 41-56.

Kaplan, M. 2018. Austin's Way with Skepticism. Oxford University Press.

Kaplan, M. 2000. “To What Must an Epistemology Be True?" Philosophy and

Phenomenological Research 61 (2): 279-304.

Kappel, K. 2010. “On Saying that Someone Knows: Themes from Craig." In A. Haddock, A. Millar, and D. Pritchard (eds.), Social Epistemology. Oxford University Press.

Kelp, C. 2011. "What's the Point of 'Knowledge' Anyway?” Episteme 8: 53-66.

Kornblith, H. 2002. Knowledge and Its Place in Nature. Oxford University Press.

Kornblith, H. 2000. "The Contextualist Evasion of Epistemology." Philosophical Issues 10: 2432.

Kvanvig, J. 2009. "The Value of Understanding." In D. Pritchard, A. Haddock, and A. Miller (eds.), Epistemic Value. Oxford University Press.

Lackey, J. and E. Sosa. 2006. The Epistemology of Testimony. Oxford University Press.

Lawlor, K. 2013. Assurance. Oxford University Press.

Machuca, D. 2015. “Conciliationism and the Menace of Skepticism.” Dialogue 4: 469-488.

Marušić, B 2010. "Skepticism Between Excessiveness and Idleness." European Journal of

Philosophy 18 (1): 60-83.

McKenna, R 2013. “'Knowledge' Ascriptions, Social Roles and Semantics.” Episteme 10 (4): $335-350$.

Neta, R. 2006. “Epistemology Factualized: New Contractarian Foundations for Epistemology." Synthese 150 (2): 247-280. 
Nolfi, K. 2017. "Functional Belief and Judgmental Belief." Synthese.

https://doi.org/10.1007/s11229-017-1510-0.

Pasnau, R. 2015. "Snatching Hope from the Jaws of Epistemic Defeat." Journal of the

American Philosophical Association 1(2): 257-275.

Pasnau, R. 2013. “Epistemology Idealized.” Mind 122 (488): 987-1021.

Pritchard, D. 2005. "Wittgenstein's On Certainty and Contemporary Anti-skepticism." In D. Moyal-Sharrock and W.H. Brenner (eds.), Readings of Wittgenstein's On Certainty. Palgrave.

Rinard, S. Forthcoming. "Pragmatic Skepticism." Philosophy and Phenomenological

Research.

Roth, P. 2003. "Review of Hilary Kornblith, Knowledge and Its Place in Nature." Notre Dame Philosophical Reviews (12).

Rysiew, P. 2012. “Epistemic Scorekeeping." In J. Brown and M. Gerken (eds.), Knowledge Ascriptions. Oxford University Press.

Rysiew, P. 2001. "The Context-Sensitivity of Knowledge Attributions." Noûs 35 (4): 477-514.

Schaffer, J. 2004. "Skepticism, Contextualism and Discrimination." Philosophy and

Phenomenological Research 69 (1): 138-155.

Sosa, E. 1991. Knowledge in Perspective: Selected Essays in Epistemology. Cambridge

University Press.

Stroud, B. 1984. The Philosophical Significance of Skepticism. Oxford University Press.

Unger, P. 1975. Ignorance: A Case for Skepticism. Oxford: Oxford University Press.

Williamson, T. 2000. Knowledge and its Limits. Oxford: Oxford University Press.

Wright, C. 1991. "Skepticism and Dreaming: Imploding the Demon." Mind 307 (1): 87-116.

\footnotetext{
${ }^{1}$ I borrow these distinctions from Aikin and Dabay (2018).

2 See Hazlett (2014), Greco (2012), and Pasnau (2015) for this distinction. Plausibly, there are close connections between what we know and what we ought to believe (see Greco 2012: 319), but I will not explore them here.

${ }^{3}$ To keep things simple, I'll speak in terms of the level of justification required for knowledge.

4 See DeRose (2017).

${ }^{5}$ See Neta (2006), Fricker (2007), Greco (2008), Henderson (2009), McKenna (2013), Gardiner (2015), Nolfi (2017), and Hannon (2019).
} 
${ }^{6}$ This is not to say that false beliefs are never useful.

${ }^{7}$ Craig calls this process "objectivization" (1990: 82-97).

8 See Hetherington (2006), BonJour (2010), and Hannon (2017) for a discussion.

${ }^{9}$ Sosa (1991: 275), Greco (2008), and Henderson (2009) make a similar point.

${ }^{10}$ Adapted from Schaffer (2004).

${ }^{11}$ See Kvanvig (2009), Kappel (2010), Kelp (2011), and Rysiew (2012) for defenses of this view.

12 See Unger (1975) and Williamson (2000).

13 See Hawthorne and Stanley (2008).

14 Thanks for Christos Kyriacou for this point.

15 Thanks to Max Hayward for this suggestion.

${ }^{16}$ See Hannon (2019).

17 See Roth (2003) for some objections.

18 See Craig (1990) and Hannon (2019) for a more thorough defense of this idea.

${ }^{19}$ We find these explanations in Unger (1975), Davis (2007), and BonJour (2010).

${ }^{20}$ Susanna Rinard (2019) develops a different view that she calls "pragmatic skepticism". The pragmatic skeptic, on her account, will admit that our beliefs lack evidential support and do not constitute knowledge, but she does not think we should give up our beliefs in light of this fact. Her pragmatic skeptic says that we have good practical reasons to retain our beliefs. I will set aside Rinard's version of pragmatic skepticism because it focuses on views that threaten our beliefs.

${ }^{21}$ See Dogramaci (2019) for this view.

22 This runs contrary to Kornblith's (2000: 26) reading of Descartes.

${ }^{23}$ I sometimes write that the skeptic has incredibly high standards for knowledge. The skeptic might disagree. She might instead argue that skepticism is motivated by certain intuitive principles; for example, if $S$ knows $P$ (i.e. having hands) entails $Q$ (i.e. not a BIV), and S knows $P$, then $S$ is in an epistemic position to know that $Q$. This doesn't seem like high-standards, says the skeptic. Neither does this principle: If $S$ is an epistemic position to know $Q$, then $S$ has evidence or reason that rules out not-Q. And the skeptic's claim that we don't have evidence or reasons to rule out skeptical hypotheses seems plausible as well (i.e. it does not rely on high standards). Unfortunately, I do not have space to tackle this other route to skepticism, but I will make two quick replies. First, it still leaves unexplained why we would have a knowledge concept that has basically no application. Second, I reject the premise that we must be in a position to know that $Q$ (i.e. not a BIV) if we are to know that $P$ (i.e. we have hands). We can know that we have hands even though it is neither reasonable to say that we know we're not BIV nor is it reasonable to say we don't know this. Neither seems quite right to say-our words sometimes fail us. This is similar to a case that Austin discusses: "Can I think of a case where a man would be neither at home nor not at home? This is inhibiting, because I think of the ordinary case where I ask 'Is he at home?' and get the answer, 'No': when certainly he is not at home. But supposing I happen first to think of the situation when I call on him just after he has died: then I see at once it would be wrong to say either... A new idiom might in odd cases be demanded." (Austin 1979: 68-9). Thus, the skeptical premise that "If you don't know that not-Q, you don't know that P" seems false. Mark Kaplan (2019: 72-4) makes this sort of reply to the skeptic. Thanks to Bryan Frances and Thomas Grundmann for raising this concern.

24 This presupposes that truth is the aim of belief, which I will grant for the sake of argument. 